\title{
Impact Factors of IT Flexibility within Cloud Technology on Various Aspects of IT Effectiveness
}

\author{
Salameh A. mjlae ${ }^{1}$ \\ Department of Computer Science \\ Balqa Applied University \\ Salt, Jordan
}

\author{
Zarina Mohamad ${ }^{2}$, Wan Suryani ${ }^{3}$ \\ Department of Computer Science \\ University Sultan Zainal Abidin \\ Besut, Malaysia
}

\begin{abstract}
Cloud computing Adoption has achieved an essential inflection factor; this is affecting IT and business models and strategies all through the industries. There is a lack of empirical evidence how the adoption of cloud technology and a certain power of cloud technology specifically, affect various aspects of information technology effectiveness as IT-helpfulness to users, user satisfaction, and IT-quality of service. The intent of this paper has been added to the main of knowledge that could be used by researchers, companies, and businesses alike to accomplish optimal outcomes with focus on the main useful power of cloud-based services, solutions, and components inside them. The research findings presented that statistical evidence that confirms factors of IT Flexibility inside-cloud computing has a much stronger correlation with several aspects of information technology effectiveness than the remainder. The new awareness gain would improve the decision making procedure for IT executives and IT managers at what time allowing for cloud computing adoption base services and solutions
\end{abstract}

Keywords-Cloud Computing Adoption (CCA); IT Flexibility (ITF); IT Effectiveness (ITF)

\section{INTRODUCTION}

Cloud adoption-based services and solutions are nowadays one of the most leading issues that IT companies face [1] Cloud computing get from a extended the past of research and enhancement on a variety of models to IT outsourcing, Cloud technology is a approach to provision and expanding IT abilities on a require and pay-per-use, with reducing costs, storage capacity, high accessibility, and more reliability represents the best advantages [2, 3, 4, 23]. Services and solutions through cloud technology as a consequence from a lot of years of investigation in the several areas include virtualization [5], networking, and software services [6], distributed computing [7], and utility computing [8]. Duncan (1995) exposed technological factors of the ITF constructs as (connectivity, modularity, and compatibility) as a measure of ITF.

These constructs provided as the foundation for subsequent researches performed by Ness (2005), Byrd and Turner (2000), [11], Tallon and Kraemer (2005). In their research, Byrd and Turner (2000) demonstrated ITF as the capability of an organizations to implement processes that be able to increase growth of the organizations. ITF also described as the fast deployment of IT components as facilitated during a company information technology infrastructure. Chebrolu (2010) expanded Ness' (2005) research by appropriately by cloud computing adoption as a proxy for ITF. As noted by Duncan (1995), an organization's IT-infrastructure could be considered flexible if innovative business processes are enabled. According to Tallon and Kraemer (2003), ITF involved the capability of a company to easily and rapidly offer new source of IT assistance for the business plan.

Fink and Newmann (2009) suggested that organizations IT infrastructures should be elastic as much as necessary to accommodate an increasingly change environments. Cloud technology can be depicted as a modern business computing paradigm extends to information technology Flexibility to improve IT capabilities through pervasive provisioning of IT services [16, 17, 24]. IT effectiveness is often considered in the context of how technology benefits the organization tangibly [18]. Cloud computing may drive ITE rather than efforts creating strategies alignment in IT base services. The failure of researchers and companies to understand cloud computing from an ITE viewpoint appear to stem from the fact that there are few investigations which evaluate the overall benefits that are achieved when the organizations adopts cloud technology base services and solutions.

\section{Problem Statement}

Increased competitive weights upon companies because of worldwide competition, expanded to all type of business are proceeding to generate, go up they require for productivity and better effectiveness between IT companies. In preparation for global economic recovery from the latest world stagnancy which began in 2007, several IT companies were evaluated their whetting their business models and management practices. IT-budgets will be lower, the business model is more focused.

The act of remove extra costs from the IT-budget and deciding regions of planned business and plan investment are important in a confined business. Come through IT solutions is leading unplanned, rapid, and recurrent change in business model alongside with the resulting demand in the lead information technology for its help essential to attain sustained competitive benefit. While cloud adoption provides some advantage include real-time provisioning and cloud consumer be billed accurately for the actual amount of its IT resource usage that can support business model into IT companies, it has its percentage of complexity in conditions of availability, performance, security, and development. The global cloud services market is expected to rise to $\$ 336$ billion by 2020 
from \$ 175 billion in 2015. The Middle East and North Africa region will see the greatest growth in cloud computing between 2014 and 2019.

Total spending on general cloud computing services in 2018 in the Middle East region will rise to $\$ 1.5$ billion compared with \$ 727 million estimated in 2014. In 2014, the Hashemite Kingdom of Jordan formed a partnership with Microsoft to implement cloud services in the public sector. Projects of the Hashemite Kingdom of Jordan that between 2014 and 2018, it's to spend on cloud technology up to $26.5 \%$ compound yearly increase rate and exceed $\$ 6$ million by 2020 Providing that a wide of services and solution of computingrelated as pay-as-you-go base open numerous opportunity for the cloud service providers in that increasing marketplace.

It is not obvious how a number of those IT companies which adopt services and solution on the cloud technology are more successful than what they were before and which solutions or services of CSP, in fact, assist which aspects of those IT companies the majority. Specifically, in light of the literature review, there was a need for empirical proof on the influence of each factor of ITF precise to cloud computing adoption on every aspect of ITF. This research is an try to verify their relationships and to attempt which, if any, factors of ITF precise to cloud technology adoption has a upper correlation with which aspect of ITE.

\section{SigNIFICANCE OF THE STUDY}

The relationship between factors of IT flexibility precise to cloud computing adoption and their aspects of information technology effectiveness among IT companies was investigated and evaluated.

In May 2010, Chief information officer of federal government IT companies offered at NIST cloud technology discussion board with a view to the adoption of services and solutions within cloud technology like Google's Earth platform, Amazon's EC2 infrastructure and Salesforce.com's in aspects of system response time, cost savings, scalability, collaboration capabilities, connectivity and consolidation. NIST started a plan to prompt adoption of cloud technology through knowing basic technical standards. The IT companies in different types of business which are prepared to adoption solutions of cloud technology without empirical evidence how factors of ITF precise to cloud technology adoption impact on the aspect of their information technology effectiveness inside IT companies and this paper provides this evidence.

\section{RESEARCH METHODOLOGY}

\section{A. Research Design}

The aim of this non-experimental quantitative correlational research was to examine and measure the relationship between factors of ITF (Compatibility, Modularity, and Connectivity) precise to cloud technology adoption and aspects of ITE The aim of this study was adding to the main of knowledge that could technically be useful by IT companies, business model, and researchers to attain the best outcome from beginning to adoption services and solutions of cloud technology. This paper was intended to work study the degree to which factors of ITF precise to cloud technology adoption correlate with different aspects of ITF in conditions of information technology capability to provide services and solutions to the IT companies in global competitions.

\section{B. The Research Work Questions}

1) To what extent, if any, is the ITF (Connectivity) specific to cloud technology adoption associated with IT quality of service between IT companies?

2) To what extent, if any, is the factor of ITF (Connectivity) specific to cloud technology adoption associated with User Satisfaction between IT companies?

3) To what extent, if any, is the factor of ITF (Connectivity) specific to cloud technology adoption associated with IT helpfulness to users between IT companies?

4) To what extent, if any, is the factor of ITF (Modularity) specific to cloud technology adoption associated with IT quality of service between IT companies?

5) To what extent, if any, is the factor of ITF (Modularity) specific to cloud technology adoption associated with User Satisfaction between IT companies?

6) To what extent, if any, is the factor of ITF (Modularity) specific to cloud technology adoption associated with IT helpfulness to users between IT companies?

7) To what extent, if any, is the factor of ITF (Compatibility) specific to cloud technology adoption associated with IT quality of service between IT companies?

8) To what extent, if any, is the factor of ITF (Compatibility) specific to cloud technology adoption associated with User Satisfaction between IT companies?

9) To what extent, if any, is the factor ITF Compatibility) specific to cloud technology adoption associated with IT helpfulness to users between IT companies?

\section{Hypotheses Test}

$\mathrm{H}_{0}$ : a factor of ITF (Connectivity) precise to cloud computing adoption was not positively associated with IT QoS, between IT companies.

H1a: a factor of ITF (Connectivity) precise to cloud computing adoption was positively associated with IT QoS, between IT companies.

H20: a factor of ITF (Connectivity) precise to cloud computing adoption was not positively associated with user satisfaction, between IT companies.

H2a: a factor of ITF (Connectivity) precise to cloud computing adoption was positively associated with user satisfaction, between IT companies.

H30: a factor of ITF (Connectivity) precise to cloud computing adoption was not positively associated with information technology helpfulness to users, between IT companies.

H3a: a factor of ITF (Connectivity) precise to cloud computing adoption was positively associated with information technology helpfulness to users, between IT companies. 
H40: a factor of ITF (Modularity) precise to cloud computing adoption was not positively associated with IT QoS, between IT companies.

H4a: a factor of ITF (Modularity) precise to cloud computing adoption was positively associated with IT QoS, between IT companies.

H50: a factor of ITF (Modularity) precise to cloud computing adoption was not positively associated with user satisfaction, between IT companies.

H5a: a factor of ITF (Modularity) precise to cloud computing adoption was positively associated with user satisfaction, between IT companies.

H60: a factor of ITF (Modularity) precise to cloud computing adoption was not positively associated with information technology helpfulness to users, between IT companies.

H6a: a factor of ITF (Modularity) precise to cloud computing adoption cloud was positively associated with information technology helpfulness to users, between IT companies.

H70: a factor of ITF (Compatibility) precise to cloud computing adoption was not positively associated with IT QoS, between IT companies.

H7a: a factor of ITF (Compatibility) precise to cloud computing adoption was positively associated with IT QoS, between IT companies.

H80: a factor of ITF (Compatibility) precise to cloud computing adoption was not positively associated with user satisfaction, between IT companies.

H8a: a factor of ITF (Compatibility) precise to cloud computing adoption was positively associated with user satisfaction, between IT companies.

$\mathrm{H} 9_{0}$ : a factor of ITF (Compatibility) precise to cloud computing adoption was not positively associated with information technology helpfulness to users, between IT companies.

H9a: a factor of ITF (Compatibility) precise to cloud computing adoption was positively associated with information technology helpfulness to users, between companies.

The purpose of this quantitative correlational study, which takes into account some suppleness in evaluated the relationships between the factors. with an end goal to keep the same reliability along with validity from prior investigate instrumentation and methods by Tallon and Kraemer [14], Ness [6], a 7-point Likert-type scale has been used to perform ordinal dataset value. Previous investigate make use of the base for sure construct elements, measures, in the role of methods for determining and measuring the construct's correlation, validity, in addition to reliability. The research from Pierce [9], Tallon and Kraemer [14] and Ness [6], besides their survey formats, utilized as a method toward accomplishing instrumentation and construct measurement.

The analysis of ordinal scale with values was managed during the chi-square test besides linear and bivariate regression test. The utilize of linear regression test for the ordinal dataset was constant by previous investigate by Pierce [9], Tallon and Kraemer [14] and Ness [6]. The survey questions on ITF by Ness [6], with proper changes to be relevant for services and solution through cloud computing, have been used as part of the whole survey instrument in this research attaining on the whole construct correlation, validity, and reliability between factors of ITF precise to cloud computing adoption and aspects of ITE.

\section{Conceptual Model}

This research's conceptual model is viewed in Fig. 1. It is an development by Tallon and Kraemer [14], Lawal [19], Ness [10] and Chebrolu [12] research, explore in depth to examine the impact factors of ITF precise to cloud computing adoption and aspects of ITE

\section{E. Operational Definition of Variables}

The components from prior investigate by Tallon and Kraemer [14], Ness [10], Chebrolu [12], and Lawal [19], have been used to evaluate the construct of ITE, while the components have been used to evaluate the construct of ITF has been used to assess the construct of factors of ITF within cloud computing and aspects of ITE. This structure of measurement was helped in achieving validity and consistency between this investigate and prior investigate. Adoption of Cloud technology had been many survey questions having already been used to evaluate each factor's power for ITE dependent on a seven-point Likert-type scale. The overall quality of the general construct on ITE was assessment during the average of the means of all construct's factors. The main factors associated to all constructs on this research were as follows: The three factors of ITF within cloud computing adoption: are compatibility (COMP), modularity (MODU) and connectivity (CONN).

- Compatibility. Refers to the capability to share, use, or connect to any kind of data across any technical component [9]. Chung, Tang, and Ahmad (2010) suggested that compatibility within organizations refers to whether the new technology will be compatible with current work practice [26].

- Modularity. Refers to how rapidly technical components can be added, changed or removed to meet new managerial conditions [9], [21], [25]. Pekkarinen (2008) suggested that modularity is the ability to integrate numerous functions within organizations to reduce service complexity and accomplish improved responsiveness to service diversity.

- Connectivity. Refers to how technical components link individuals, functional areas, and applications in organizations to enhance communication and resource sharing throughout an organization. This association could be within or outside of the customary confines of the organization [9], [27].

- Information technology effectiveness. Is often considered in the context of how the technology benefits the organization tangibly [22],[28]. 


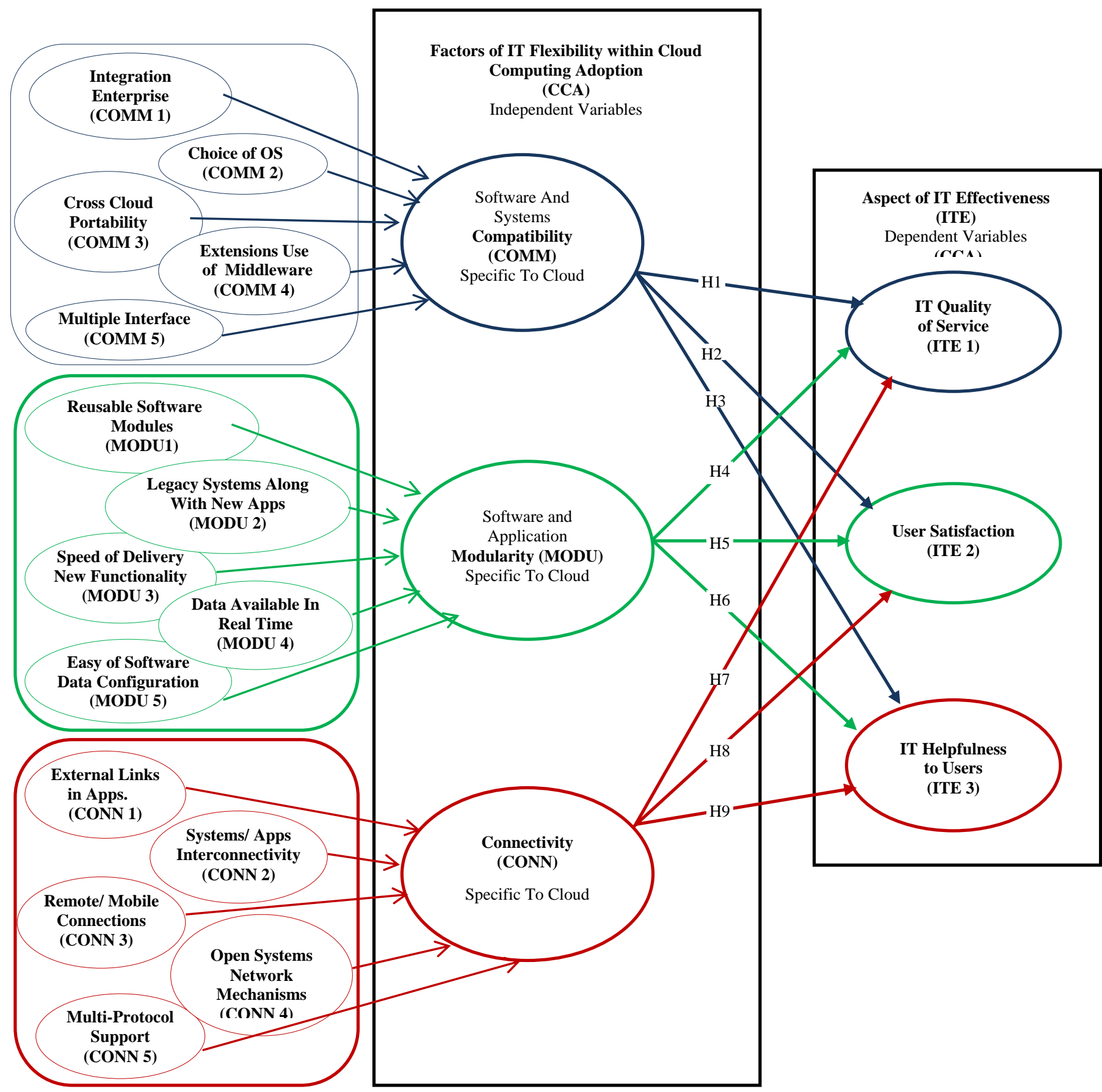

Fig. 1. Shows Conceptual Model.

Information Technology Effectiveness Elements: The main items that were utilized to assess Information Technology effectiveness construct have been taken from previous investigate by Gurbaxani, and Tallon Kraemer, which they utilized to evaluate the model of strategic flexibility. Ness [10] affirmed that aspects had been used to evaluate strategic flexibility appear to be close up associated operationally and provide the good origin to evaluate ITE. These aspects are the overall QoS (ITEF1), user satisfaction with IT (ITEF2) and helpfulness of IT staff to users (ITEF3). This research has been consistency with the previous investigators in concepts of methodology, and so a seven-point Likert-type scale has been used when data gathering and analyze, which represent dataset elements with a view to measurement convenient to size or quality. In linear regression analyze, it is verified that independent variables (IV) in the gather data had a normal distribution before to test.

\section{F. Sample}

The sampling method was used from previous investigators were pursued to some extent probable to do again validity and reliability. The aboard population for this research wants to be those who had a broad knowledge of information technology adds to its business model. Including ( CIO, Associate CIO, 
Interim CIO, Acting CIO, Global CIO, and Co-CIO). in the position of chief information officer were precise to be content with this population condition. The Survey with Google Forms have been used to draw a random sample of 1221 email addresses of IT staff in a variety of departments within IT companies including sizes (small \& medium) from the sampling. A whole of 149 responded were received, in which 132 respondents complete the questionnaire. Seventeen respondents were excluded for not achieving the set conditions. On the 41days, the questionnaire was closed because a appropriate sample was accomplished. Unlike similar studies done by Chebrolu [12], were focused on all size and different business type of IT companies .this research paper is focused on only IT companies within size small and medium only.

\section{G. Instrumentation}

The study instrument contains questions that have been proposed to collection data from the participants on IT and cloud technology adoption. The origin of the current research survey instrument has been established on the research done by Lawal [19] and Ness [10], on ITF and ITE. The survey was a mixture of the original survey questions that have been produced by Gurbaxani, Tallon and Kraemer, [13], additionally later have been used by Tallon and Kraemer [14], Chebrolu [12], Ness [10], Lawal [19] and Mjlae[29], for ITF and ITE. The survey questions for ITF have been changed minimally to be appropriate for adoption of cloud computing. In order to recreate the original questionnaire survey, the format and design of the prior questionnaire survey were maintained to add reliability and validity. All questions have been used seven-point Likert-type scale.

\section{H. Data Collection and Analysis}

Data has been gathered utilized an online survey instrument. A whole of 149 participants had responded to the survey questionnaire from among 1221 eligible participants list, but only 132 participants provide full answers question. The survey results were downloaded from the Services of Google forms web site. The data has been then moved to IBM SPSS Software version 22. The bi-variate linear regression analysis has been executing as an affirmation to the chi-square outcomes has been obtained. The power of every one relationship between COMP, MODU, CONE, ITEF1, ITEF2, and ITEF3 was evaluate based on the statistical significance value calculated for all factors in addition to the correlation coefficients.

\section{FINDINGS}

\section{A. Validity and Reliability}

As indicated the G*Power 3.1, a sample size of 119 was suggested to accomplish the statistical power needed to build up the validity of this research. The survey sample gathered by docs.google.com/forms was totaled 149. Also, a total of Cronbach's Alpha score of 0.805 has been calculated from standardized items that substantiate the interior consistency of this research. Norusis [20] suggested a Cronbach's Alpha score of minimum 0.5 to set up the reliability of a study's measures. These statistical tests have presented that the data has been used in this research are both reliable and valid. Only 143 participants have been answered all 15 questions as several participants select to avoid some questions. Norusis [20] suggested that before calculating a correlation coefficient, a test for data outliners ought to be prepared to avoid misleading outcomes. Whisker plot and A box were done using the entire 143 response data. The whisker plot and box identified three response dataset $(35,40,82)$ for ITEFs outside of interquartile scope; while it was recognized sex response datasets $(35,40$, 82, 97, 101, 131) for CONE and MODU; and identified eleven response datasets $(8,14,19,28,35,40,82,97,101,112,131)$ for COMP outside of interquartile scope. Norusis [20] warn that any data outliners the whisker scope in whisker plot and the box is well chosen an extreme value and should be delete from the total replies data set. as a result, the data sets $(8$, $14,19,28,35,40,82,97,101,112$, and 131) were deleted from this research remain 132 answers intended for the test.

\section{B. Analysis and Evaluation}

1) Linear regression analysis and bivariate correlations: the total answer dataset to 132, an inter level correlation analysis has been executed on every one paired constructs such as CONN-ITEF1, CONN-ITEF2, CONN-ITEF3, MODU-ITEF1, MODU-ITEF2, MODU-ITEF3, COMPITEF1, COMP- ITEF2, and CMOP-ITEF3 as shown in table (2). The array of variables in the bi-variate correlations analysis has been made to ITEF1, ITEF2, ITEF3 were the target dependent variables whereas Connectivity (CONN), Modularity (MODU) and Compatibility (COMP) were the independent variables(IV). The outcome of the analysis was depend on Phi/Pearson's value exposed that positive correlations was existed between CONN - ITEF at $r=.758(\mathrm{p}$ $\left.<.001, \mathrm{r}^{2}=.574\right)$; MODU - ITFE at $\mathrm{r}=.772\left(\mathrm{p}<.001, \mathrm{r}^{2}=\right.$. 595), and between COMP - ITEF at $r=.741\left(\mathrm{p}<.001, \mathrm{r}^{2}=\right.$ .549 ). The linear regression analysis was validated the bivariate correlation test outcome by generating the exact calculations.

2) Pearson's chi-square test: The Pearson's chi-squared analysis outcome with 132 response data sets as show in table [2], which stand at 335.729, $\mathrm{p}<.001$ for CONN -ITEF1; at 352.392, $\mathrm{p}<.001$ for CONN -ITEF2; 310.497, $\mathrm{p}<.001$ for CONN -ITEF3; 349.114, $\mathrm{p}<.001$ for MODU - ITEF1; 428.361, p < .001 for MODU -ITEF2; 358.983, p <.001 for MODU -ITEF3; 330.701, $\mathrm{p}<.001$ for COMP ITEF1; 359.974, $\mathrm{p}<.001$ for COMP -ITEF2; 350.377, $\mathrm{p}<.001$ for COMP -ITEF3. All the relationships between aspects of ITEF and factors of IT flexibility within cloud computing (CONN, MODU, and COMP) are statistically significant because of $\mathrm{p}-$ value $<.001$ in case of all of them

3) Scatter plot analysis: According to Norusis [7], the heteroscedasticity or inequality of regressions, represent a sequence of random variables with various variances, and therefore square-root transformations are usually used for positive data when addressing the assumption of heteroscedasticity in linear regression analyses. All the paired constructs of CONN -ITEF1, CONN - ITEF2, CONN -ITEF3, MODU -ITEF1, MODU -ITEF2, MODU -ITEF3, COMP ITEF1, COMP -ITEF2, and COMP -ITEF3 all found to have positive slopes. The technique of square-root transformation 
for the ITEF1, ITEF2, and ITEF3 constructs was used for further analysis. However, the same kinds of slopes with similar $\mathrm{r} 2$ linear values are obtained.

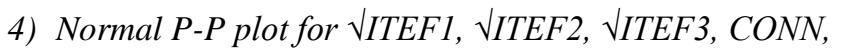
$M O D U$, and COMP: According to Norusis [20], an assumption of hypothesis testing is a normal distribution of values of the dependent variables. To show that $\sqrt{I T E F} 1, \sqrt{I T E F} 2$, and $\sqrt{\mathrm{ITEF}} 3 \mathrm{had}$ normal distribution at the reduced response dataset of 132, the observed increasing probability was plotted against the estimated cumulative probability for $\sqrt{\mathrm{ITEF}} 1, \sqrt{\mathrm{ITEF}} 2$, and $\sqrt{\mathrm{ITEF}}$. It was found that the standardized values represent the normal distribution of the dependent variables and agree with the condition of homoscedasticity for linear regression analysis. Hence, the 132 data sets represent in $\sqrt{ }$ ITEF1, $\sqrt{ }$ ITEF2, $\sqrt{ }$ ITE.F3 for this research were convincing and applicable for parametric linear regression test. In the same way, the pragmatic cumulative probability was plotted beside the expected increasing probability for three independent variables (CONN, MODU, COMP) to ensure that the 132 datasets were applicable and suitable for linear regression test.

5) The chi-square, linear regression, and bivariate correlations analysis with $\sqrt{ }$ ITEF (1-3): the Chi-square, linear regression, and bivariate correlations analysis were executed by the $\sqrt{ }$ ITFE transformation for all paired constructs and found out that $\left(\mathrm{r}^{2}\right)$ - values of each one correlation is roughly the same values as shown in Table II.

The Linear Regression analysis and Bivariate Correlations for each factor of IT flexibility within cloud computing and Aspects of ITEF: The linear regression and bivariate correlations analyses were executed for every of the 45 paired constructs as shown in Table III (15 factors of IT flexibility within cloud computing times 3 aspects of ITEF). Also, discovered that MODU1 * ITEF2 $\left(\mathrm{r}^{2}=.511, \mathrm{p}<.001\right)$ have the strongest correlation between all probably paired constructs at the level of factors of IT flexibility within cloud computing have been utilized in the research. The all pairs in terms of correlation values $\left(r^{2}\right)$ are as shown in Table III. the paired of constructs relating two Sub-factors of Compatibility (COMP) variable make it to the list as their $\left(\mathrm{r}^{2}\right)$ values were lower than 0.150 , whereas all paired constructs remaining relating Subfactors of Modularity (MODU), CONN1 (External Links in Applications), COMP5(Multiple Interface), CONN2 (Systems/Apps Interconnectivity) and MODU2(Legacy Systems Along With New Apps) have been stronger correlations with each precise aspect of information technology effectiveness (ITEF1, ITEF2, ITEF3) that have been utilized in this Research. Also, COMP1 (Integration Enterprise) have fewer correlations with each precise aspect of information technology effectiveness (ITEF1, ITEF2, ITEF3).

\section{Test of Hypotheses}

An assessment of the investigation findings has been executing to evaluation the researcher's hypotheses. The strength and direction of the relationships between the variables were an assessment by the $\left(\mathrm{r}^{2}\right)$ value of every correlation computation. The $\left(\mathrm{r}^{2}\right)$ values as shown in Table II represent the inter-scale correlation results for IV (ITEF1, ITEF2, ITEF3) which along with p-value have been used to accept, or reject nine hypotheses. The nine null hypotheses have been rejected because the p-value of .000 was less than the significance level of .05 to test [20].

TABLE I. THE CHI-SQUARE CRosstabs, LINEAR REgRESSION AND BIVARIATE CORRELATION ANALYSIS RESULTS FOR FACTORS OF ITF WITHIN CLOUD COMPUTING AND ITEF

\begin{tabular}{|l|l|l|l|l|}
\hline Variable & Pearson Chi-Square & Pearson's R & R-Square(r2) & Sig. (2-tailed) (p) \\
\hline Connectivity * IT Effectiveness & 646.441 & .758 & .574 & $.000(<.001)$ \\
\hline Modularity * IT Effectiveness & 764.211 & .772 & .595 & $.000(<.001)$ \\
\hline Compatibility * IT Effectiveness & 767.691 & .741 & .549 & $.000(<.001)$ \\
\hline
\end{tabular}

TABLE II. The CHI-SQUARE CROSSTABs, LINEAR REgRESSION AND BIVARIATE CORRELATION ANALYSIS RESULTS FOR FACTORS OF ITF WITHIN CLOUD COMPUTING VERSUS ASPECTS OF ITEF

\begin{tabular}{|l|l|l|l|l|}
\hline Variable & $\begin{array}{l}\text { Pearson } \\
\text { Chi-Square }\end{array}$ & Pearson's Correlation (r) & R-Square (r2) & Sig. (2-tailed) (p) \\
\hline Connectivity * ITEF1 & 335.729 & .709 & .502 & $.000(<.001)$ \\
\hline Connectivity * ITEF2 & 352.392 & .711 & .505 & $.000(<.001)$ \\
\hline Connectivity * ITEF3 & 310.497 & .653 & .426 & $.000(<.001)$ \\
\hline Modularity * ITEF1 & 349.114 & .695 & .483 & $.000(<.001)$ \\
\hline Modularity * ITEF2 & 428.361 & .727 & .528 & .470 \\
\hline Modularity * ITEF3 & 358.983 & .686 & .454 & $.000(<.001)$ \\
\hline Compatibility * ITEF1 & 330.701 & .674 & .467 & $.000(<.001)$ \\
\hline Compatibility * ITEF2 & 359.974 & .684 & .444 & $.000(<.001)$ \\
\hline Compatibility * ITEF3 & 350.377 & .667 & $.000(<.001)$ \\
\hline
\end{tabular}


TABLE I. THE LINEAR REGRESSION AND BIVARIATE CORRELATION ANALYSIS RESULTS FOR THE TOP TEN FACTORS OF ITF WITHIN CLOUD COMPUTING VERSUS ASPECTS OF ITEF

\begin{tabular}{|c|c|c|c|c|}
\hline No & Variable & Pearson's Correlation (r) & R-Square (r2) & Sig. (2-tailed) (p) \\
\hline & MODU1 * ITEF2 & 0.715 & 0.511 & $.000(<.001)$ \\
\hline & CONN1 * ITEF2 & 0.66 & 0.436 & $.000(<.001)$ \\
\hline & COMP5 * ITEF1 & 0.657 & 0.432 & $.000(<.001)$ \\
\hline & MODU1 * ITEF3 & 0.635 & 0.403 & $.000(<.001)$ \\
\hline & COMP5 * ITEF2 & 0.627 & 0.393 & $.000(<.001)$ \\
\hline & CONN2 $*$ ITEF 1 & 0.615 & 0.378 & $.000(<.001)$ \\
\hline & CONN2 * ITEF2 & 0.615 & 0.378 & $.000(<.001)$ \\
\hline & MODU2 * ITEF1 & 0.614 & 0.377 & $.000(<.001)$ \\
\hline & COMP4 * ITEF3 & 0.613 & 0.376 & $.000(<.001)$ \\
\hline & CONN1 $*$ ITEF1 & 0.609 & 0.371 & $.000(<.001)$ \\
\hline & CONN1 $*$ ITEF3 & 0.606 & 0.367 & $.000(<.001)$ \\
\hline & MODU1 * ITEF1 & 0.602 & 0.362 & $.000(<.001)$ \\
\hline & CONN3 $*$ ITEF1 & 0.6 & 0.360 & $.000(<.001)$ \\
\hline & CONN5 * ITEF1 & 0.592 & 0.350 & $.000(<.001)$ \\
\hline & COMP4 * ITEF1 & 0.588 & 0.346 & $.000(<.001)$ \\
\hline & CONN2 * ITEF3 & 0.584 & 0.341 & $.000(<.001)$ \\
\hline & MODU5 * ITEF3 & 0.575 & 0.331 & $.000(<.001)$ \\
\hline & MODU4 * ITEF2 & 0.574 & 0.329 & $.000(<.001)$ \\
\hline & CONN5 * ITEF2 & 0.572 & 0.327 & $.000(<.001)$ \\
\hline & CONN3 * ITEF2 & 0.57 & 0.325 & $.000(<.001)$ \\
\hline & MODU4 * ITEF1 & 0.567 & 0.321 & $.000(<.001)$ \\
\hline & MODU5 * ITEF2 & 0.56 & 0.314 & $.000(<.001)$ \\
\hline & MODU5 * ITEF1 & 0.553 & 0.306 & $.000(<.001)$ \\
\hline & MODU2 * ITEF2 & 0.545 & 0.297 & $.000(<.001)$ \\
\hline & MODU2 * ITEF3 & 0.534 & 0.285 & $.000(<.001)$ \\
\hline & CONN3 * ITEF3 & 0.532 & 0.283 & $.000(<.001)$ \\
\hline & COMP4 * ITEF2 & 0.526 & 0.277 & $.000(<.001)$ \\
\hline & COMP5 * ITEF3 & 0.52 & 0.270 & $.000(<.001)$ \\
\hline & MODU3 * ITEF2 & 0.518 & 0.268 & $.000(<.001)$ \\
\hline & COMP3 * ITEF3 & 0.518 & 0.268 & $.000(<.001)$ \\
\hline & MODU4 * ITEF3 & 0.515 & 0.265 & $.000(<.001)$ \\
\hline & COMP2 * ITEF3 & 0.511 & 0.261 & $.000(<.001)$ \\
\hline & CONN4 * ITEF2 & 0.508 & 0.258 & $.000(<.001)$ \\
\hline & CONN4 * ITEF1 & 0.497 & 0.247 & $.000(<.001)$ \\
\hline & COMP2 $*$ ITEF 2 & 0.496 & 0.246 & $.000(<.001)$ \\
\hline & COMP3 * ITEF2 & 0.496 & 0.246 & $.000(<.001)$ \\
\hline & CONN5 * ITEF3 & 0.494 & 0.244 & $.000(<.001)$ \\
\hline & MODU3 * ITEF3 & 0.49 & 0.240 & $.000(<.001)$ \\
\hline & COMP2 * ITEF1 & 0.479 & 0.229 & $.000(<.001)$ \\
\hline & CONN4 * ITEF3 & 0.475 & 0.226 & $.000(<.001)$ \\
\hline & MODU3 * ITEF1 & 0.455 & 0.207 & $.000(<.001)$ \\
\hline & COMP3 * ITEF1 & 0.435 & 0.189 & $.000(<.001)$ \\
\hline & COMP1 * ITEF2 & 0.425 & 0.181 & $.000(<.001)$ \\
\hline & COMP1 * ITEF1 & 0.373 & 0.139 & $.000(<.001)$ \\
\hline & COMP1 * ITEF3 & 0.34 & 0.116 & $.000(<.001)$ \\
\hline
\end{tabular}




\section{1) Hypothesis 1: CONN associated with ITEF1}

$\mathrm{H}_{1}$ : a factor of ITF (Connectivity) precise to cloud computing adoption was not positively associated with IT QoS, among IT companies.

H1a: a factor of ITF (Connectivity) precise to cloud computing adoption was positively associated with IT QoS, among IT companies.

\section{Finding 1: $\mathrm{H}_{0}$ Rejected}

The factor of ITF (Connectivity) precise to cloud computing adoption did positively correlate with IT QoS. The values for CONN as shown in Table II confirmed a positive correlation between a factor of ITF (Connectivity) precise to cloud computing adoption and ITEF1. The values for CONN were $\mathrm{r}=.709, \mathrm{r}^{2}=.502, \mathrm{p}<.001$; hence, the findings confirmed a positive correlation with IT QoS.

\section{2) Hypothesis 2: CONN associated with ITEF2}

$\mathrm{H} 1_{0}$ : a factor of ITF (Connectivity) precise to cloud computing adoption was not positively associated with user satisfaction, among IT companies.

H1a: a factor of ITF (Connectivity) precise to cloud computing adoption was positively associated with user satisfaction, among IT companies.

\section{Finding 2: $\mathrm{H} 2{ }_{0}$ Rejected}

The factor of ITF (Connectivity) precise to cloud computing adoption did positively correlate with user satisfaction. The values for CONN as shown in Table II confirmed a positive correlation between a factor of ITF (Connectivity) precise to cloud computing adoption and ITEF2. The values for CONN were $r=.711, \mathrm{r}^{2}=.505, \mathrm{p}<.001$; hence, the findings confirmed a positive correlation with user satisfaction.

\section{3) Hypothesis 3: CONN associated with ITEF3}

$\mathrm{H} 3_{0}$ : a factor of ITF (Connectivity) precise to cloud computing adoption not positively associated with information technology helpfulness to users, among IT companies.

H3a: a factor of ITF (Connectivity) precise to cloud computing adoption was positively associated with information technology helpfulness to users, among IT companies.

\section{Finding 3: $\mathrm{H} 3_{0}$ Rejected}

The factor of ITF (Connectivity) precise to cloud computing adoption did positively correlate with IT helpfulness to users. The values for CONN as shown in Table II confirmed a positive correlation between a factor of ITF (Connectivity) precise to cloud computing adoption and ITEF3. The values for CONN were $r=.653, r^{2}=.426, p<.001$; hence, the findings confirmed a positive correlation with IT helpfulness to users.

\section{4) Hypothesis 4: MODU associated with ITEF1}

$\mathrm{H}_{4}$ : a factor of ITF (Modularity) precise to cloud computing adoption was not positively associated with IT QoS, among IT companies.
H4a: a factor of ITF (Modularity) precise to cloud computing adoption was positively associated with IT QoS, among IT companies.

\section{Finding 4: $\mathrm{H} 4_{0}$ Rejected}

The factor of ITF (Modularity) precise to cloud computing did positively correlate with IT QoS. The values for MODU as shown in Table II confirmed a positive correlation between a factor of ITF (Modularity) precise to cloud computing adoption and ITEF1. The values for MODU were $r=.695, r^{2}=.483$, $\mathrm{p}<.001$; hence, the findings confirmed a positive correlation with IT QoS.

\section{5) Hypothesis 5: MODU associated with ITEF2}

$\mathrm{H} 5_{0}$ : a factor of ITF (Modularity) precise to cloud computing adoption cloud was not positively associated with user satisfaction, among IT companies.

H5a: a factor of ITF (Modularity) precise to cloud computing adoption was positively associated with user satisfaction, among IT companies.

\section{Finding 5: $\mathrm{H}_{0}$ Rejected}

The factor of ITF (Modularity) precise to cloud computing adoption did positively correlate with user satisfaction. The values for MODU as shown in Table II confirmed a positive correlation between a factor of ITF (Modularity) precise to cloud computing adoption and ITEF2. The values for MODU were $\mathrm{r}=.727, \mathrm{r}^{2}=.528, \mathrm{p}<.001$; hence, the findings confirmed a positive correlation with user satisfaction.

\section{6) Hypothesis 6: MODU associated with ITEF3}

$\mathrm{H6}_{0}$ : a factor of ITF (Modularity) precise to cloud computing adoption was not positively associated with information technology helpfulness to users, among IT companies.

H6a: a factor of ITF (Modularity) precise to cloud computing adoption was positively associated with information technology helpfulness to users, among IT companies.

\section{Finding 6: $\mathrm{H6}_{0}$ Rejected}

The factor of ITF (Modularity) precise to cloud computing adoption did positively correlate with information technology helpfulness to users. The values for MODU as shown in Table II confirmed a positive correlation between a factor of ITF (Modularity) precise to cloud computing adoption and ITEF3. The values for MODU were $r=.686, \mathrm{r}^{2}=.470, \mathrm{p}<.001$; hence, the findings confirmed a positive correlation with information technology helpfulness to users.

\section{7) Hypothesis 7: COMP associated with ITEF1}

$\mathrm{H}_{0}$ : a factor of ITF (Compatibility) precise to cloud computing adoption was not positively associated with IT QoS, among IT companies

H7a: a factor of ITF (Compatibility) precise to cloud computing adoption was positively associated with IT QoS, among IT companies.

Finding 7: $\mathrm{H} 7_{0}$ Rejected 
The factor of ITF (Compatibility) precise to cloud computing adoption did positively correlate with IT QoS. The values for COMP as shown in Table 2 confirmed a positive correlation between a factor of ITF (Compatibility) precise to cloud computing adoption and ITEF1. The values for COMP were $\mathrm{r}=.674, \mathrm{r}^{2}=.454, \mathrm{p}<.001$; hence, the findings confirmed a positive correlation with IT QoS.

\section{8) Hypothesis 8: COMP associated with ITEF2}

$\mathrm{H} 8_{0}$ : a factor of ITF (Compatibility) precise to cloud computing adoption was not positively associated with user satisfaction, among IT companies.

H8: a factor of ITF (Compatibility) precise to cloud computing adoption was positively associated with user satisfaction, among IT companies.

\section{Finding 8: $\mathrm{H}_{0}$ Rejected}

The factor of ITF (Compatibility) precise to cloud computing adoption did positively correlate with user satisfaction. The values for COMP as shown in Table 2 confirmed a positive correlation between a factor of ITF (Compatibility) precise to cloud computing adoption and ITEF2. The values for COMP were $\mathrm{r}=.684, \mathrm{r}^{2}=.467, \mathrm{p}<.001$; hence, the findings confirmed a positive correlation with user satisfaction.

\section{9) Hypothesis 9: COMP associated with ITEF3}

$\mathrm{H}_{9}$ : a factor of ITF (Compatibility) precise to cloud computing adoption was not positively associated with information technology helpfulness to users, among IT companies.

H9a: a factor of ITF (Compatibility) precise to cloud computing adoption was positively associated with information technology helpfulness to users, among IT companies.

Finding 9: $\mathrm{H}_{0}$ Rejected

The factor of ITF (Compatibility) precise to cloud computing adoption did positively correlate with information technology helpfulness to users. The values for COMP as shown in Table II confirmed a positive correlation between a factor of ITF (Compatibility) precise to cloud computing adoption and ITEF3. The values for COMP were $\mathrm{r}=.667$, $\mathrm{r}^{2}=.444, \mathrm{p}<.001$; hence, the findings confirmed a positive correlation with information technology helpfulness to users.

These findings are reliable with previous investigate been done by Lawal [19], Ness [10] and Chebrolu [12] which confirmed a positive correlation between factors of ITF (compatibility, modularity, and connectivity) within cloud technology and ITE. Setting a bar on the $r^{2}$ values from Table II as greater than 0.40 , the conceptual model diagram is updated see Fig. 2. Similarly, depending on the values from Table II, and with a bar on the $\mathrm{r}^{2}$ values as greater than 0.40 , a minimized conceptual model diagram for Sub-Factors of ITF precise to Cloud Computing Adoption and aspects of ITE as shown in Fig. 3.

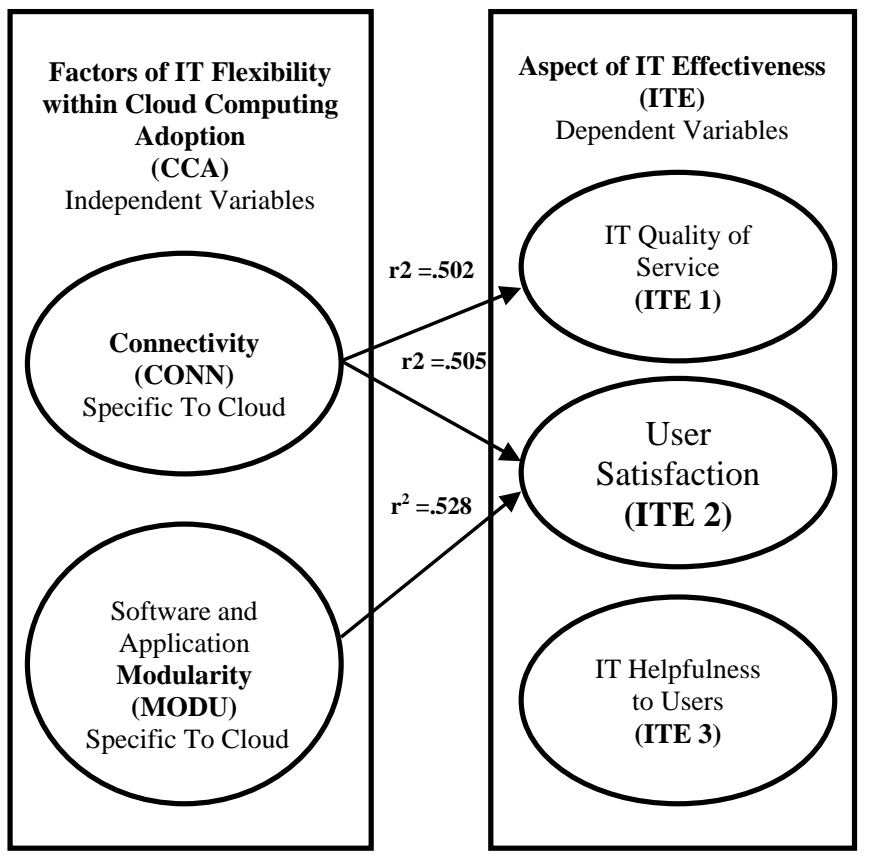

Fig. 2. Updated Conceptual Model for Factors of ITF Specific to the Cloud and Various Aspects of ITFE with $\mathrm{r}^{2}$ Values $<0.40$.

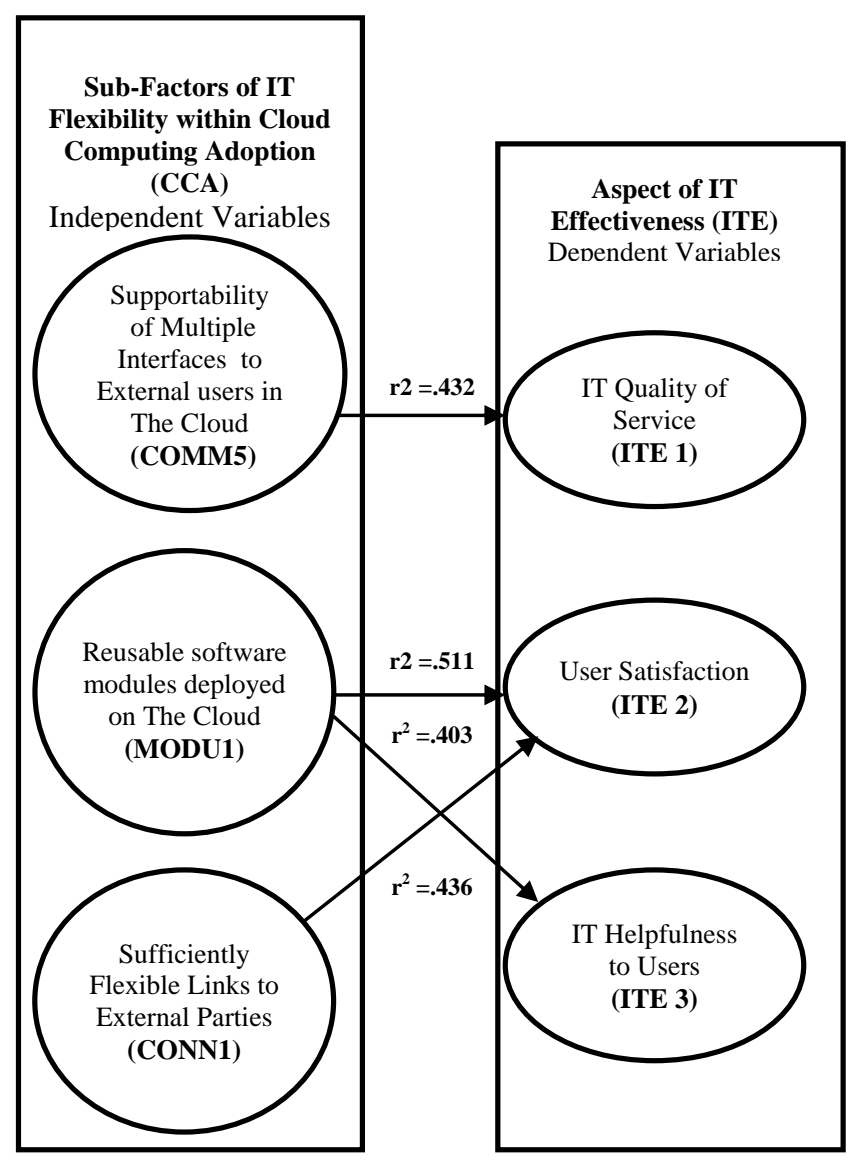

Fig. 3. Minimized Conceptual Model for Factors of ITF Specific to the Cloud and Various Aspects of ITE with $r^{2}$ Values $<0.40$. 


\section{SUMMARY}

This paper presented new empirical evidence that correlation between factor of ITF Modularity (MODU) specific to cloud and User Satisfaction (ITEF2) has the highest correlation $\left(\mathrm{r}=.727, \mathrm{r}^{2}=.528, \mathrm{p}<.001\right)$ among fife paired constructs at the level of cloud computing capabilities have been utilize in this research, followed by Connectivity (CONN) precise to cloud with User Satisfaction (ITEF2) ( $\mathrm{r}=.711$, $\left.\mathrm{r}^{2}=.505, \mathrm{p}<.001\right)$, Connectivity $(C O N N)$ precise to cloud with information technology QoS (ITEF1) ( $\mathrm{r}=.709, \mathrm{r}^{2}=.502$, $\mathrm{p}<.001$ ), Modularity (MODU) precise to cloud with information technology QoS (ITEF1) $\left(\mathrm{r}=.695, \mathrm{r}^{2}=.483, \mathrm{p}<.001\right)$ and Modularity (MODU) precise to cloud with IT Helpfulness To Users (ITEF3) $\left(\mathrm{r}=.686, \mathrm{r}^{2}=.470, \mathrm{p}<.001\right)$. Which are the three paired constructs with lower than 0.20 of their $\mathrm{r}^{2}$ values? Correlation between Compatibility (COMP) precise to cloud with information technology QoS (ITEF1) has correlation $\left(\mathrm{r}=.335, \mathrm{r}^{2}=.189, \mathrm{p}<.001\right)$,Compatibility (COMP) with User Satisfaction (ITEF2) has correlation $\left(r=.425, \mathrm{r}^{2}=.181, \mathrm{p}<.001\right)$ and Compatibility (COMP) with information technology Helpfulness To Users (ITEF3) has correlation $\left(r=0.34, r^{2}=.116\right.$, $\mathrm{p}<.001)$.This paper presented new proof that several Factors of ITF precise Cloud Computing have been utilizing in this paper have a much higher impact on ITF than others have. Some authors have researched the impact of various constructs on ITE among IT companies, either as paired factors to evaluation business model and value through competitive benefit. On the other hand, this paper has been filled in the knowledge gap in the literature review because it concentrates on the impact of fifteen various aspects of cloud technology within IT companies.

\section{IMPLICATIONS}

To determine the prioritization and dominance of modularity (MODU) precise to cloud over cloud connectivity (CONN) and compatibility (COMP) precise to cloud on several aspects of ITE (ITEF1, ITEF2, ITEF3), (see Table I). IT managers and IT executives could more effectively decide where, how and which Factors of ITF (Connectivity, Modularity, Compatibility) used of adoption of cloud computing toward assign financial resources for the implementation, maintenance, and deployment of their complex IT frameworks in their companies. The linear regression analysis has been used in this research confirmed that Modularity precise to the cloud is more dominant than connectivity precise to cloud additionally, connectivity more dominant than compatibility precise to cloud on different aspects of ITE. The implication of this investigate finding is that IT managers and IT executives should assign increasingly financial resources toward software and application modularity inside cloud than resources to connectivity and software and systems compatibility precise to cloud to enhancing ITE.

IT executives and managers should assign additional financial resources towards MODU1 (reusable software modules) and MODU2(legacy systems along with new apps) which are the top two subfactors of ITF specific to the cloud which has a higher positive impact on different aspects of ITE as listed in Fig. 2. The findings from this research represented only firms in the Hashemite Kingdom of Jordan; the results should be interpreted as representing the IT sector.

Lastly, since the participants were IT manager that is playing a CIO role in different IT companies, the research findings in this paper have contribution on the current knowledge of the relationships between Factors of information technology Flexibility precise Cloud Computing adoption (compatibility, modularity, connectivity), and several aspects of ITE has been used in this paper.

The findings addressed the benefits of used Factors and subfactors of ITF within Cloud Computing on aspects of ITE and would improve the decision making the procedure for IT executive and manager when taking into consideration the cloud computing adoption and its business models.

\section{RECOMMENDATIONS}

The study's recommendations are that IT executives and managers should assign increasingly financial resources toward software and application modularity inside cloud technology than resources to cloud connectivity and software and systems compatibility inside cloud in order to enhance their ITE, This research could be repeated with a quantitative method with the same variables on how a precise type of cloud service model IaaS, PaaS and SaaS or how a precise type of deployment model public, private and hybrid would impact on ITE . Additionally, the author recommends that this study be repeated with a similar quantitative correlative study to analyze the same variables by another type of business with more precise. IT managers could use this new knowledge and awareness when allocate financial resources and their human to enhancing their ITE and deliver services and solutions through the cloud to their business in a dynamic market.

\section{COnClusions AND Future Work}

This study contributed to the limited literature regarding cloud computing adoption and implementation among IT Organizations in Jordan. The findings from the study provided statistical evidence that the combination of the three factors of ITF (compatibility, modularity, and connectivity), have a positive relationship with ITE.

The inferences of this study for researchers encompass the inclusion of other forms of ITF in future studies that could improve comprehension of the phenomenon, and enhance ITE. Further, the present research analyzed ITF and effectiveness, associated with cloud adoption and implementation from the perspective of IT companies. Within the Jordan, this study could also be extended by taking into consideration the perspective of cloud-based vendors and analyzing the challenges they encounter in deploying their solutions at IT companies. Also, this study was based on any of the cloud computing service models.

Additionally, the results of this research can be used in the educational, health, industrial and governmental sectors to improve performs. 


\section{ACKNOWLEDGMENT}

We would like to thank Universiti Sultan Zainal Abidin for the financial support to this project under the Mentor-Mentee Grant (Unisza/Mentor mentee/2018/023).

\section{REFERENCES}

[1] Pólkowski, Z. D. Z. I. S. L. A. W., et al. "Improving business processes by Cloud Computing in SMEs "Zeszyty Naukowe Uczelni Jana Wyżykowskiego. Studia z Nauk Technicznych(2017).

[2] Gens, F. (2009). New IDC IT cloud services survey: Top benefits and challenges [Web log message]. Retrieved from http://blogs.idc.com/ie/?p=730

[3] Ramzan, Muhammad, et al. "An Analysis of Issues for Adoption of Cloud Computing in Telecom Industries" Engineering, Technology \& Applied Science Research 8.4 (2018): 3157-3161.

[4] Suess, J., \& Morooney, K. (2009). Identity management \& trust services: Foundations for cloud computing. EDUCAUSE Review, 44(5), 24. Retrieved December 20, 2009, from ABI/INFORM Global. (Document ID: 1865415041).

[5] Perez, J., Germain-Renaud, C., Kegl, B., \& Loomis, C. (2009). Responsive, elastic computing. Paper presented at the GMAC '09: Proceedings of the 6th International Conference Industry Session on Grids Meets Autonomic Computing, Barcelona, Article (CrossRef Link).

[6] Vouk, M.A. (2008). Cloud computing-Issues, Research, and Implementations. Paper presented at the ITI 2008: Proceedings of the 30th International Conference on Information Technology Interfaces, Cavtat, Croatia. 31-4. Article (CrossRef Link).

[7] Skala, Karolj, et al. "Scalable distributed computing hierarchy: Cloud, fog and dew computing. "Open Journal of Cloud Computing (OJCC) 2.1 (2015): 16-24.

[8] Nikolov, Peter, Bert Armijo, and Vladimir Miloushev. "Globally distributed utility computing cloud. " U.S. Patent No. 9,578,088. 21 Feb. 2017.

[9] Duncan, N. B. (1995). Capturing flexibility of information technology infrastructure: a study of resource characteristics and their measure. Journal of Management Information Systems, 12(2), 37-57 Article (CrossRef Link).

[10] Ness, L. R. (2005). Assessing the relationship among information technology flexibility, strategic alignment, and information technology effectiveness (Doctoral dissertation). Retrieved from ProQuest Dissertations and Theses database. (UMI No. 3178531)

[11] Byrd, T. A. \& Turner, D. E. (2000). "Measuring the Flexibility of Information Technology Infrastructure: Exploratory Analysis of a Construct," Journal of Management Information Systems, 17(1), 167208. Article (CrossRef Link).

[12] Chebrolu, S. B. (2010). Assessing the relationships among cloud adoption, strategic alignment, and information technology effectiveness. From ProQuest Dissertations \& Theses database. (No. AAT 3426510).

[13] Tallon, P.P., Kraemer K.L. (2003a). Investigating the relationship between strategic alignment and IT business value: The discovery of a paradox. University of California, Irvine. Retrieved March 12, 2004, [Online]Available:http://www.crito.uci.edu/publications/pdf/Alignment Paradox.pdf

[14] Tallon, P. P., Kraemer, K. L., \& Gurbaxani, V. (2000). Executives' perceptions of the business value of information technology: A process- oriented approach. Journal of Management Information Systems, 16(4), 145-173. Retrieved from http://www.jmis-web.org/issues/Spring_2000/ index.html Article (CrossRef Link).

[15] Fink, Lior, and Seev Neumann. "Exploring the perceived business value of the flexibility enabled by an information technology infrastructure. " Information \& Management 46.2 (2009): 90-99. Article (CrossRef Link).

[16] Sultan, Nabil. "Cloud computing for education: A new dawn? "International Journal of Information Management 30.2 (2010): 109116. Article (CrossRef Link).

[17] Garrison, Gary, Robin L. Wakefield, and Sanghyun Kim. "The effects of IT capabilities and delivery model on cloud computing success and firm performance for cloud supported processes and operations "International Journal of Information Management 35.4 (2015): 377393. Article (CrossRef Link).

[18] Saleem I, Qureshi T.M., Mustafa S, Anwar F. and Hijazi T. (2011). Role of Information and Communicational Technologies in perceived Organizational Performance: An Empirical Evidence from Higher Education Sector of Pakistan. Business Review. 6(1): 81-93.

[19] Lawal, HildaLyn. Information Technology Flexibility and Effectiveness, Specific to Cloud Computing Adoption within Small and Medium Enterprises. Northcentral University, 2014.

[20] Norusis, M. (2008b). SPSS Statistics 17.0 Statistical Procedures Companion. Upper Saddle- River, N.J.: Prentice Hall.

[21] Pekkarinen, S., \& Ulkuniemi, P. (2008). Modularity in developing business services by platform approach. The International Journal of Logistics Management, 19(1), 84-103.

[22] Saleem, D. I. (2011). Role of Information and Communicational Technologies in perceived Organizational Performance: An Empirical Evidence from Higher Education Sector of Pakistan. Business Review, 6(1), 81-93.

[23] Serrano, N., Gallardo, G., \& Hernantes, J. (2015). Infrastructure as a service and cloud technologies. IEEE Software, 32(2), 30-36.

[24] Dahiya, D., \& Mathew, S. K. (2016). IT assets, IT infrastructure performance and IT capability: a framework for egovernment. Transforming Government: People, Process and Policy, 10(3), 411-433.

[25] Benitez, J., Ray, G., \& Henseler, J. (2018). Impact of information technology infrastructure flexibility on mergers and acquisitions. MIS Quarterly, 42(1), 25-43.

[26] Hentschel, R., Leyh, C., \& Baumhauer, T. (2019, January). Critical Success Factors for the Implementation and Adoption of Cloud Services in SMEs. In Proceedings of the 52nd Hawaii International Conference on System Sciences.

[27] Isal, Y. K., Pikarti, G. P., Hidayanto, A. N., \& Putra, E. Y. (2016). Analysis of IT infrastructure flexibility impacts on IT-Business strategic alignment. Journal of Industrial Engineering and Management (JIEM), 9(3), 657-683.

[28] Baysari, M. T., Lehnbom, E. C., Li, L., Hargreaves, A., Day, R. O., \& Westbrook, J. I. (2016). The effectiveness of information technology to improve antimicrobial prescribing in hospitals: a systematic review and meta-analysis. International journal of medical informatics, 92, 15-34

[29] [1] Mjlae, S. A., Zarina, M., \& Suryani, W. (2019). Impact Aspects of IT Flexibility Specific To Cloud Computing Adoption on IT Effectiveness. Journal of Theoretical and Applied Information Technology, 97(2), 1041-1059. Retrieved from http://www.jatit.org/volumes/Vol97 No3/ 28Vo197No3.pdf 